\title{
REVIEW
}

\section{Endothelial Glycocalyx Hyaluronan}

\section{Regulation and Role in Prevention of Diabetic Complications}

\author{
Gangqi Wang, Gesa L. Tiemeier, Bernard M. van den Berg, and Ton J. Rabelink
}

From the Division of Nephrology, Department of Internal Medicine, the Einthoven Laboratory for Vascular and Regenerative Medicine, Leiden University Medical Center, Leiden, the Netherlands

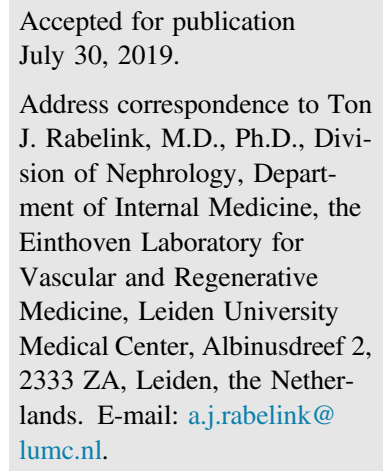

\begin{abstract}
The endothelial glycocalyx is critically involved in vascular integrity and homeostasis, by regulating vascular permeability, regulating mechanotransduction, and reducing inflammation and coagulation. The turnover of the glycocalyx is dynamic to fine-tune these processes. This is in particular true for its main structural component, hyaluronan (HA). Degradation and shedding of the glycocalyx by enzymes, such as hyaluronidase 1 and hyaluronidase 2, are responsible for regulation of the glycocalyx thickness and hence access of circulating cells and factors to the endothelial cell membrane and its receptors. This degradation process will at the same time also allow for resynthesis and adaptive chemical modification of the glycocalyx. The (re)synthesis of HA is dependent on the availability of its sugar substrates, thus linking glycocalyx biology directly to cellular glucose metabolism. It is therefore of particular interest to consider the consequences of dysregulated cellular glucose in diabetes for glycocalyx biology and its implications for endothelial function. This review summarizes the metabolic regulation of endothelial glycocalyx $\mathrm{HA}$ and its potential as a therapeutic target in diabetic vascular complications. (Am J Pathol 2020, 190: 781-790; https://doi.org/10.1016/j.ajpath.2019.07.022)
\end{abstract}

The endothelial cell is surrounded by a negative-charged gel-like layer, the glycocalyx, which serves as a barrier between blood and vessel wall. This membrane-bound part of the endothelial glycocalyx consists of proteoglycans, glycosaminoglycans (GAGs), glycoproteins, and glycolipids. GAGs are the main contributors to the endothelial glycocalyx structure and function, of which heparan sulfate (HS) and hyaluronan (HA) constitute up to $90 \% .^{1-3}$ Plasma proteins, such as albumin, orosomucoid, antithrombin III, extracellular superoxide dismutase, lipases, growth factors, and chemokines, associate with the glycocalyx, ${ }^{3}$ thus constituting a bioactive surface layer. The endothelial glycocalyx is critically involved in vascular integrity and homeostasis, where it regulates endothelial cell mechanotransduction, vascular permeability, coagulation, and inflammation. ${ }^{3,4}$ The binding capacity of glycocalyx, and in particular its HS component, to various growth factors and chemokines regulates endothelial activation states and cross communication with neighboring cells. ${ }^{3,5}$ In a physiological state, glycocalyx synthesis and degradation are dynamically regulated to maintain and adapt endothelial function. During chronic disease conditions, such as diabetes, atherosclerosis, hypertension, and sepsis, the endothelial glycocalyx may lose its structure or become compositionally modified. Both modification and degradation of the endothelial glycocalyx can further result in endothelial dysfunction, vascular inflammation, coagulation, and transendothelial protein leakage and thus contribute to the development of (micro)vascular disease. ${ }^{3,6-8}$

Endothelial HA appears to be key in many of the glycocalyx functions. It has recently been demonstrated that

Supported by the Dutch Kidney Foundation grant C08.2265 and GLYCOREN consortium C09.03; and the China Scholarship Council grant 201406170050 (G.W.).

Disclosures: None declared.

This article is part of a review series on glycocalyx in human disease. 
diabetes is associated with loss of endothelial HA, whereas genetic disruption of endothelial HA synthesis phenocopies the vascular lesions and organ damage that can be observed in diabetes. ${ }^{7}$ The current review specifically discusses how this particular endothelial glycocalyx component is regulated and how it plays a role in the development of diabetic complications. A more general review of glycocalyx function and the role of the HS component in diabetes was discussed recently elsewhere. ${ }^{9}$

\section{Hyaluronan Biosynthesis}

HA is a linear polysaccharide that is composed of repeating units of glucuronic acid (GlcA) and $N$-acetyl-glucosamine (GlcNAc) linked together through glycosidic bonds. ${ }^{10}$ In contrast to synthesis of the other GAGs, which takes place in the Golgi apparatus, HA is synthesized at the inner plasma membrane and subsequently secreted into the extracellular space by membrane-protruding hyaluronan synthases (HAS1, HAS2, and HAS3). After its synthesis, HA interacts with specific surface proteins (hyaladherins), such as CD44, or is assembled into the pericellular extracellular matrix. ${ }^{6,11}$ In mammalian cells, the three HAS isoenzymes differ in distribution and functional properties and respond to different stimuli. ${ }^{10,12,13}$ Among the three HASs, HAS1 expression is the lowest in healthy cells ${ }^{14}$; it requires higher substrate concentrations ${ }^{15}$ and production of $\mathrm{HA}$ is slowest. ${ }^{15}$ On stimulation, HAS3 can produce large amounts of HA but of a lower molecular weight. ${ }^{10}$ HAS2 is the most widespread isoform, which is also correlated to HA distribution. ${ }^{12}$ HAS2 knockout mice die early in gestation because of major defects in cardiovascular development, suggesting that HA may function as molecular platform for vascular signaling. ${ }^{16}$ All three HASs have been shown to produce extracellular HA, whereas HAS1 also produces intracellular HA. ${ }^{14}$ With regard to the endothelium, current findings argue for HAS2 as the main enzyme involved in endothelial homeostasis and HA production. ${ }^{7}$

The HA biosynthesis rate in vitro is 10 to 30 monosaccharides/second for recombinant streptococcal HAS. ${ }^{17}$ In optimal conditions ( $\mathrm{pH} 6.5$ to 10.5), purified streptococcal HAS could polymerize HA at a rate of approximately 240 monosaccharides/second. ${ }^{18}$ This high synthesis rate raises the point that the cytosolic availability of uridine diphosphoglucuronic acid (UDP-GlcA) and uridine diphosphate $\mathrm{N}$-acetylglucosamine (UDP-GlcNAc), the two substrates for HA synthesis, could be critical for HA synthesis. ${ }^{19-22}$ Because of the high affinity of transporters located on the Golgi membrane for sugar nucleotides, UDP sugars are quickly pumped into the Golgi to keep levels at saturation in the Golgi but at the same time may result in low cytosolic availability of UDP-GlcA and UDP-GlcNAc levels for HA biosynthesis. Furthermore, cytosolic UDP-GlcA concentration is also lower than
UDP-GlcNAc, ${ }^{15}$ which makes it a potential rate-limiting factor for HA production by HAS. In agreement, reduced endothelial HA surface expression was observed after knockdown of the enzymes UDP-glucose pyrophosphorylase 2 or UDP-glucose 6-dehydrogenase that control the concentrations of UDP-GlcA in endothelial cells. ${ }^{23}$ By contrast, overexpression of UDP-glucose 6dehydrogenase induces HA production without changing the synthesis of the other GAGs ${ }^{20}$ further underlining the dependency of glycocalyx HA synthesis on the substrate UDP-GlcA. UDP-GlcNAc, the other component of the polysaccharide $\mathrm{HA}$, is more abundant in the cytosol. Besides acting as a substrate for HA synthesis, it also directly regulates HAS2 protein stability and mRNA expression through O-GlcNAcylation. ${ }^{24,25}$

The synthesis rate of HA also depends on the activity of the HAS2 enzyme. HAS2 protein has a rapid turnover, with a half-life of 17 minutes in the absence of O-GlcNAcylated serine 221, whereas O-GlcNAcylation of serine 221 on HAS2, regulated by UDP-GlcNAc, greatly increases its stability at the membrane. ${ }^{24}$ This allows for a substantial increase in HA production. Other factors are also involved in the modulation of HAS2 gene expression, HAS2 activity, and thus HA synthesis (Figure 1). HAS2 forms dimers or oligomers to form the pores in the membrane, necessary for protruding the newly synthesized HA. This pore formation is regulated by ubiquitination. ${ }^{26}$ For example, mutation of the ubiquitin site on lysine 190 of HAS2 leads to inactivation of its enzymatic activity. ${ }^{26}$ HAS2 is the sole GAGproducing enzyme that can be regulated by the main energy sensor, AMP activated protein kinase (AMPK), where phosphorylation of threonine 110 of HAS2 by AMPK inhibits HAS2 enzymatic activity. ${ }^{27}$ The AMPK-mediated inhibition of HA production probably serves cellular energy homeostasis as HA production is a high-energy consuming process given the high synthesis rate: the biosynthesis of UDP-GlcA and UDP-GlcNAc requires one and two ATPs, respectively. ${ }^{19}$ The subsequent translocation of one HA disaccharide unit across the membrane costs energy equivalent to one ATP. ${ }^{28}$

\section{Hyaluronan Degradation}

In the vasculature, HA is mainly incorporated into the glycocalyx and extracellular matrix, whereas the plasma level of HA is low in healthy people, because of the rapid removal of HA from the circulation by liver and kidney. ${ }^{29}$ Degradation of HA is efficient, with a half-life of 2 to 6 minutes and a total normal turnover of 10 to $100 \mathrm{mg} / \mathrm{day}$ in the blood of adult human. ${ }^{30}$ This process is greatly dependent on the activity of hyaluronidases, which are a family of enzymes that can degrade HA into HA fragments by hydrolyzing the disaccharides at hexosaminidic $\beta$ (1 to 4$)$ linkages. Six hyaluronidases have been identified in humans: HYAL1, HYAL2, HYAL3, HYAL4, SPAM1 


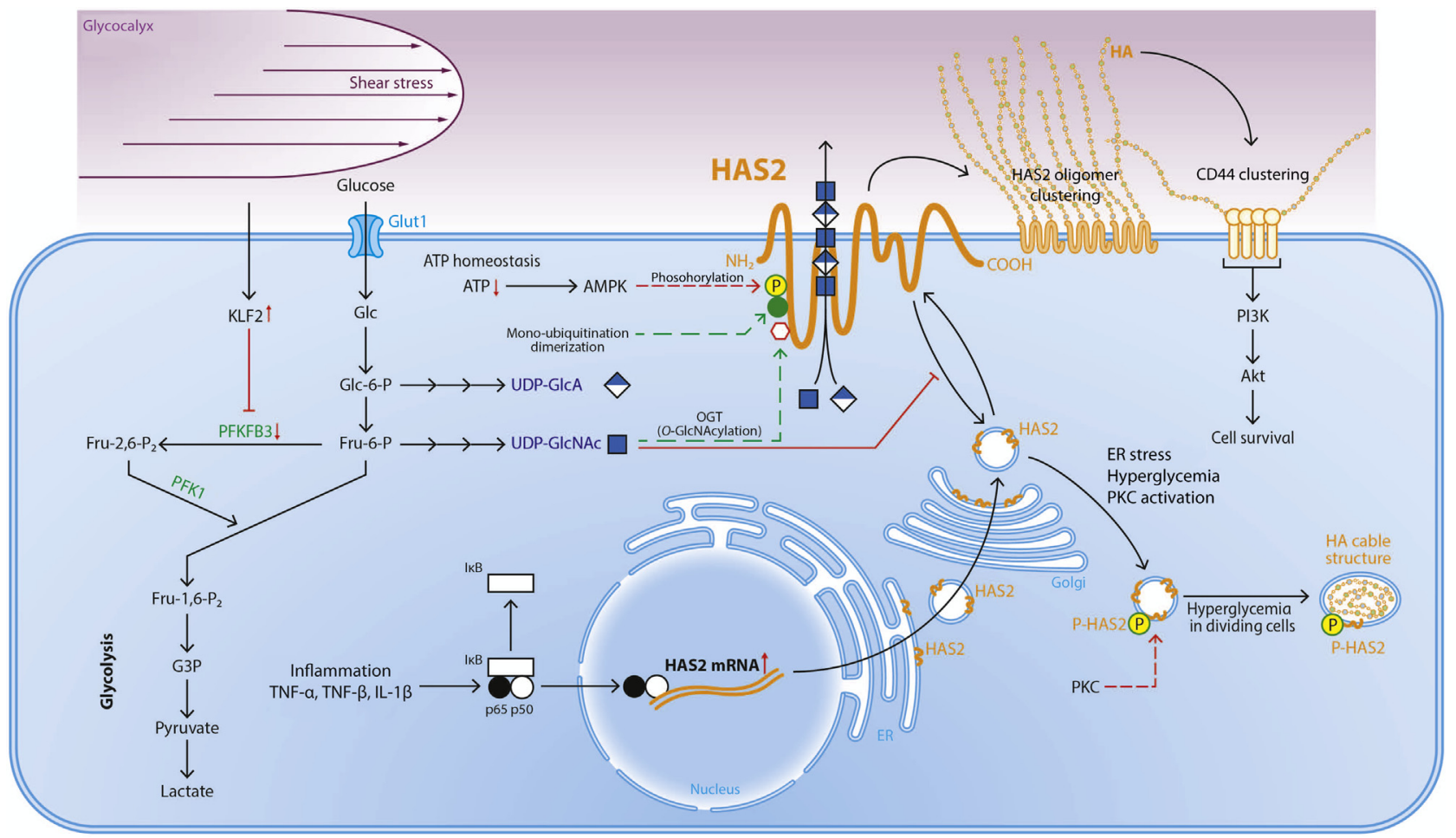

Figure 1 Schematic overview of hyaluronan (HA) biosynthesis regulation. Hyaluronan synthase 2 (HAS2) is the main enzyme involved in endothelial homeostasis and HA production. The availability of uridine diphosphoglucuronic acid (UDP-GlcA) and uridine diphosphate N-acetylglucosamine (UDP-GIcNAc) determine HA synthesis by HAS2. Shear stress, through Krüppel-like factor 2 (KLF2) activation and subsequent inhibition of the glycolytic activator 6phosphofructo-2-kinase/fructose-2,6-biphosphatase 3 (PFKFB3), allows glucose intermediates to shuttle into the biosynthetic pathways of UDP-GlcA and UDPGlcNAc. UDP-GlcNAc formation also leads to 0-GlcNAcylation of serine 221 on HAS2 protein, which greatly increases HAS2 stability on the membrane and reduces its endocytosis. Ubiquitination of HAS2 protein activates its enzymatic activity through forming HAS2 dimers or oligomers. As an ATP homeostasis sensor, AMP-activated protein kinase (AMPK) inhibits HAS2 activity by regulating the phosphorylation of threonine 110 of HAS2. On endoplasmic reticulum (ER) stress, triggered by hyperglycemia-induced protein kinase C (PKC) pathway in dividing cells or proinflammatory cytokines, HAS2 can be activated on the ER membrane to produce cable-like HA structure embedded in aggresomes intracellularly. Proinflammatory cytokines, such as tumor necrosis factor $\alpha$ (TNF- $\alpha$ ), TNF- $\beta$, and IL-1 $\beta$, can induce HAS2 expression through NF- $\mathrm{KB}$ pathway activation. Normal HA increases CD44 clustering and promotes cell survival. Akt, protein

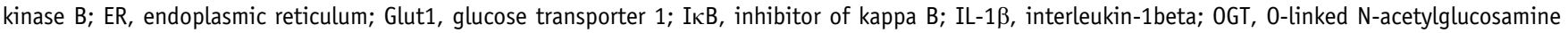
(GlcNAc) transferase; Fru-6-P, fructose-6-phosphate; Fru-2,6- $P_{2}$, fructose-2,6-biphosphate; Fru-1,6- $\mathrm{P}_{2}$, fructose-1,6-biphosphate; G3P, glyceraldehyde 3phosphate; Glc, glucose; Glc-6-P, glucose-6-phosphate; PFK1, phosphofructokinase 1; P-HAS2, phosphorylated-HAS2; PI3K, phosphatidylinositol 3-kinase; PKC, protein kinase C.

(PH-20), and HYAL6P, ${ }^{31}$ of which HYAL1 and HYAL2 are the predominant isoforms in most tissues. HYAL2 is at the cell surface and anchored to the plasma membrane by a glycosylphosphatidylinositol link. It can cleave highmolecular-weight HA to a product of approximately 20 $\mathrm{kDa}$ (roughly 50 disaccharide units). ${ }^{4,32}$ These fragments functionally enhance inflammatory and angiogenic signaling. ${ }^{33,34}$ HA fragments, bound to CD44 (eg, promote endothelial cell proliferation and migration), ${ }^{33}$ stimulate monocyte activation in a toll-like receptor 4-dependent manner. ${ }^{34}$ The HYAL2 generated HA fragments are hypothesized to subsequently become internalized and delivered to endosomes and lysosomes, where intracellular HYAL1 degrades the 20-kDa fragments to small HA oligosaccharides. ${ }^{32}$ Interestingly, it is has been proposed that HYAL1 can also be taken up from the circulation and subsequently become activated in the endosome, as it requires a low pH (3 to 4) to be functional. ${ }^{4}$ In support for this model of HA degradation, HYAL2-deficient mice show a thicker endothelial glycocalyx than control mice. ${ }^{35}$ Although no human HYAL2 deficiency has been reported, knockdown of HYAL2 in mice showed extremely high HA plasma levels, underpinning the role of HYAL2 in HA homeostasis. ${ }^{35,36}$ HYAL1-deficient mice likewise display a thicker glycocalyx and are also protected from endothelial dysfunction in early diabetes mellitus, ${ }^{37}$ underlining the relevance of this enzyme system in regulating glycocalyx function. Injection of active bovine testes HYAL, which is active at a higher $\mathrm{pH}$, in the circulation of rats also greatly reduces the endothelial HA surface presence and damage to the endothelial glycocalyx structure (Figure 2). Finally, a rare case of genetic HYAL1 deficiency, in turn, also showed a dramatic elevation of plasma HA. ${ }^{39}$

Cell migration-inducing hyaluronidase 1 and cell migration-inducing hyaluronidase 2 are the most recent identified HA binding proteins exhibiting HA degrading activity. $^{40,41}$ Cell migration-inducing hyaluronidase 1 , which is present in various organs, ${ }^{42}$ is a secreted protein 

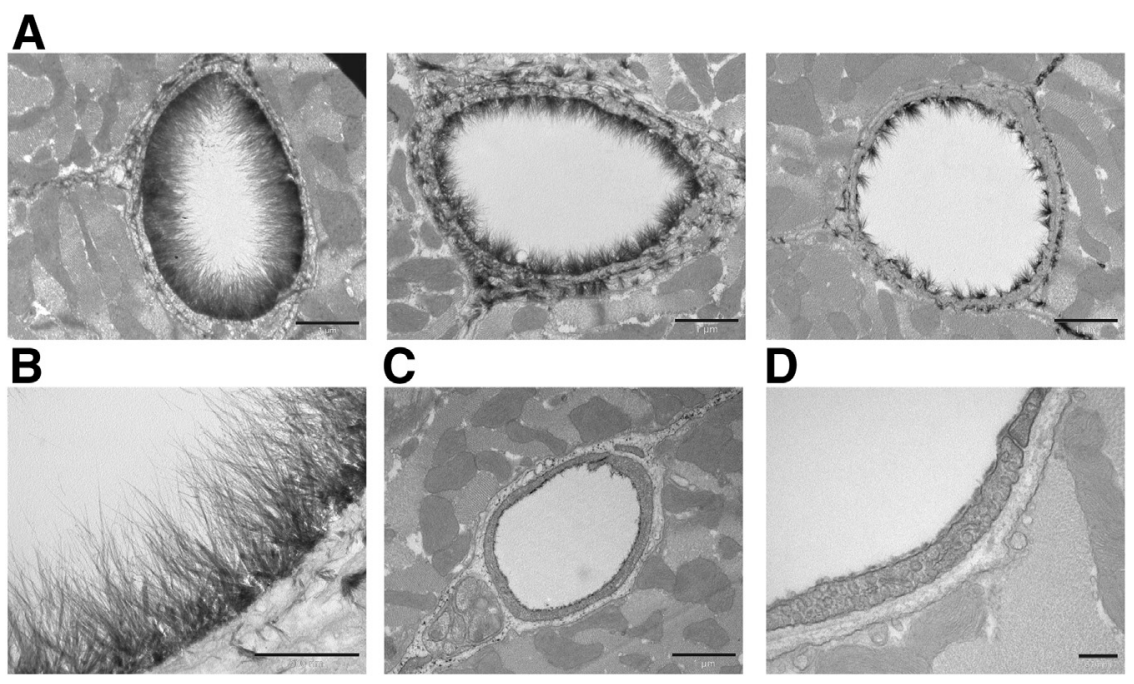

D

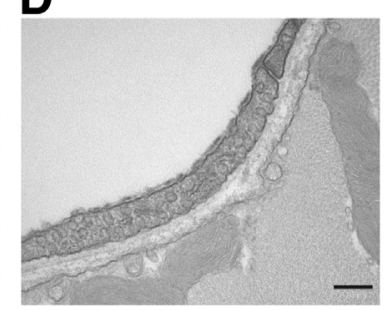

Figure 2 Removing endothelial glycocalyx hyaluronan by hyaluronidase treatment leads to loss of the endothelial glycocalyx structure. A: 0n perfusion staining of rat left ventricular vasculature with Alcian Blue 8GX, capillary endothelial cell surfaces are stained with a thick layer varying in dimension, as shown in the transmission electron microscopic overviews. B: Detail of normal capillary glycocalyx. C: Degrading hyaluronan from the endothelial surface reveals a residual staining, with loss of the hair-like structures resulting in a different appearance and smaller dimension. D: Detail of remaining capillary glycocalyx after hyaluronidase treatment. The experiment setting and staining protocol were published previously by van den Berg et al. ${ }^{38}$ Scale bars: $1 \mu \mathrm{m}$ (A and $\left.\mathbf{C}\right) ; 0.5$ $\mu \mathrm{m}$ (B); $20 \mathrm{~nm}$ (D). that contains a $\mathrm{N}$-terminal signal sequence, ${ }^{43}$ and requires participation of the clathrin-coated pit pathway to degrade HA. ${ }^{40}$ Cell migration-inducing hyaluronidase 2 (alias transmembrane protein 2), is expressed on the cell surface as a transmembrane structure. It can specifically degrade highmolecular-weight HA into approximately 5-kDa fragments at $\mathrm{pH} 6$ to 7 in a contact-dependent manner. Cell migration-inducing hyaluronidase 2 is thought to be involved in the initial step of HA catabolism before internalization and degradation in the lysosome. ${ }^{41,43}$

Except for enzymatic degradation by hyaluronidase, HA can also be directly chemically degraded. Especially reactive oxygen species (ROS), derived from superoxide anion radicals $\left(\mathrm{O}_{2}^{-}\right)$and nitrogen monoxide $\left({ }^{\bullet} \mathrm{NO}\right)$, including hydrogen peroxide, peroxynitrite, and hypochlorous acid, have been shown to cause direct depolymerization of HA. ${ }^{44-47}$

\section{Hyaluronan Function in the Endothelial Glycocalyx}

As a main component of the endothelial glycocalyx, HA contributes to its structure and gel-like properties. The nonsulfated HA is not covalently linked to any core protein, unlike HS, but instead it deeply penetrates the glycocalyx, attached to endothelial membrane-bound proteins, such as CD44. ${ }^{3}$ Various techniques have been used to visualize the polysaccharide composition of the endothelial glycocalyx. ${ }^{2,7}$ Recently, using super-resolution optical microscopy, HA was shown as long molecules that form a hexagonal network covering the endothelial luminal surface, whereas HS is a shorter molecule perpendicular to the cell surface. ${ }^{48}$ This HA network is critical to the integrity and function of the endothelial glycocalyx. Permeation of the luminal capillary glycocalyx is by and large determined by its HA component. Treatment of the endothelium with hyaluronidase leads to loss of the capillary filtration barrier to plasma proteins and results in edema formation and proteinuria. ${ }^{38,49,50}$ Furthermore, the presence of $\mathrm{HA}$ at the endothelial surface is required for endothelial mechanosensing and maintenance of endothelial quiescence. $^{51,52}$ The endothelial glycocalyx has long been recognized as a molecular scaffold critical for growth factor binding, generation of chemokine gradients, and surfacereceptor organization. ${ }^{5}$ Although this research has been mostly focused on the HS component, where the negatively charged sulfate groups and iduronic acid residues in the HS chain are critical for presentation and concentration of protein ligands, ${ }^{9}$ more data are becoming available that show a role for HA as well in modulation of growth factor and chemokine gradients at the endothelial surface. For example, binding of tumor necrosis factor- $\alpha$-induced protein 6 to HA inhibits chemokine-stimulated transendothelial migration of neutrophils via a direct interaction between tumor necrosis factor$\alpha$-induced protein 6 and the HA-binding site of CXCL8. ${ }^{53}$ HA also hosts a specific binding site for angiopoietin 1, and loss of HA synthesis is thus associated with loss of endothelial angiopoietin 1 signaling and local vascular destabilization. ${ }^{7}$ Although these HA-mediated interactions promote endothelial quiescence and vessel stability under basal conditions, HA and HA fragments can also interact with the CD44 and the receptor for HA-mediated motility to coregulate endothelial activation. CD44 is a classic transmembrane receptor that is present on various cell types and is regulated by inflammation. ${ }^{54}$ For example, T lymphocytes use CD44 to bind to HA and start engaging with the endothelium. ${ }^{54}$ The endothelium itself can also express CD44, which then stimulates angiogenic signaling events in the endothelium. ${ }^{55,56}$ The receptor for HA-mediated motility functions on the one hand as an intracellular receptor, where it associates with microtubules in the cell and is involved in endothelial cell migration. ${ }^{57}$ It can, however, also be exported to the extracellular surface during cytokine exposure, where it binds both HA and CD44 and further induces endothelial cell activation and angiogenesis. ${ }^{58}$ Finally, glycocalyx components, including HA, have also 
been shown to regulate plasma membrane shape, increasing membrane extensions that can further serve communication between cells and the extracellular matrix. ${ }^{59}$

\section{Endothelial Hyaluronan in Diabetes}

Endothelial cells play an essential role in glucose and insulin delivery from blood to organs. Impaired insulin signaling in the endothelial cells, with reduction of insulin receptor substrate 2 expression and insulin-induced endothelial nitric oxide synthase phosphorylation, reduces insulin-induced glucose uptake by the skeletal muscle via decreased capillary recruitment and decreased interstitial insulin concentrations in the skeletal muscle. ${ }^{60}$ Insulin rapidly increases glycocalyx accessibility for circulating blood in muscle, and this is associated with an increased blood volume in individual capillaries. ${ }^{61}$ Hyaluronidase treatment of the glycocalyx abolishes the effects of insulin on capillary blood volume and impairs insulin-mediated glucose disposal. ${ }^{61,62}$ These studies suggest that endothelial HA in the glycocalyx is related to insulin homeostasis.

Endothelial dysfunction is not only associated with insulin resistance but also one of the major causes of diabetic vascular complications, including macroangiopathies and microangiopathies. Human kidney tissue demonstrated progressive loss of glomerular capillary endothelial HA with diabetic nephropathic lesion formation, which was accompanied by loss of other glycocalyx constituents on the endothelial surface as well. ${ }^{7}$ With increasing severity of diabetic lesions, accumulation of matrix deposition of HA could be observed, which, however, was no longer related to the endothelium and the glycocalyx. Endothelial-specific deletion of HA resulted in vascular destabilization, characterized by capillary ballooning, mesangiolysis, and loss of endothelial fenestrations. This led to albuminuria and secondary glomerulosclerosis, thus phenocopying the diabetic renal lesions. ${ }^{7,63,64}$ Similarly, retinal and myocardial capillary destabilization could be observed. These data underline the relevance of endothelial HA and proper glycocalyx function in prevention of diabetic complications.

In type 1 diabetic patients, using glycocalyx permeable and impermeable tracers and orthogonal polarization spectral microscopy, systemic glycocalyx volume was reported to be decreased, whereas microvascular sublingual glycocalyx properties were affected, allowing more red blood cells to penetrate this layer. ${ }^{65}$ Furthermore, plasma HA and HYAL1 levels were also elevated. ${ }^{65,66}$ Similarly, these changes have also been reported for type 2 diabetic patients, in which also retinal glycocalyx dimensions were reduced and the transcapillary escape rate of albumin was increased. ${ }^{67}$

\section{Regulation of Endothelial Glycocalyx Hyaluronan in Diabetes}

As diabetes is associated with altered cellular glucobiosynthesis and oxidation-reduction state, ${ }^{68}$ it may perhaps not come as a surprise that endothelial HA homeostasis, which is so closely interconnected with these processes, becomes dysregulated as well. Impaired biosynthesis secondary to reprioritization of glucose metabolism away from the HA glucobiosynthetic pathways appears, however, a less likely explanation for the loss of endothelial glycocalyx HA. During hyperglycemia, excess glucose uptake activates the metabolic hexosamine pathway, resulting in increased production of UDP-GlcNAc. ${ }^{69}$ Increased UDP-GlcNAc concentrations enable, as discussed above, the increase of both HAS2 gene expression and enzyme stability through O-GlcNAcylation, which should result in elevated HA production. It is, on the other hand, still not clear how the UDP-GlcA pool, which is regarded as the rate-limiting factor for HA biosynthesis, changes in diabetes. Interestingly, UDP-GlcA also functions as a substrate for the glucuronidation reaction to decrease the intracellular lipid and fatty acid toxicity, ${ }^{70,71}$ which could limit its availability for HA synthesis in diabetic conditions.

ROS production has been well established as a cause of endothelial dysfunction in diabetes. ${ }^{72}$ Under diabetic conditions, endothelial cells produces large amounts of ROS in both cytosol and mitochondria, mainly caused by activation of the protein kinase $\mathrm{C}$, polyol, and hexosamine pathways as well as reduction of the pentose phosphate pathway flux. ${ }^{73}$ Besides changing cellular metabolic pathways, ROS induced excess formation of advanced glycation end products, which cause photo-induced HA degradation. ${ }^{74}$ Proinflammatory cytokines, such as tumor necrosis factor- $\alpha$, tumor necrosis factor- $\beta$, and IL- $1 \beta$, in diabetes also can induce HAS2 expression through $\mathrm{NF}-\kappa \mathrm{B}$ pathway activation. ${ }^{75}$ Furthermore, diabetes-induced endothelial activation, via induced protein kinase $\mathrm{C}$ activation, has been shown to induce the formation of intracellular HA-cable-like structures that are secreted as HA aggregates and have been shown to trigger monocyte adhesion. ${ }^{76,77}$

On endothelial cell activation, platelet-derived HYAL2 degrades HA from the surface of endothelial cells into fragments, capable of further inducing immune responses by monocytes. ${ }^{78}$ HYAL2 has been shown to induce glycocalyx impairment in cultured endothelial cells under low shear stress. ${ }^{79}$ Both ROS and proinflammatory cytokines have been reported to induce HYAL2 expression in epithelial cells. ${ }^{80,81}$ How endothelial HYAL2 activity changes in response to diabetes has not been investigated thus far. HYAL1 is found to be elevated in the blood of type 1 diabetes, in both human and animal models, as well as in type 2 diabetic patients, ${ }^{37,65,67,82}$ which is correlated with the plasma HA content. ${ }^{66}$ Proinflammatory cytokines, such as tumor necrosis factor- $\alpha$ and IL-1 $\beta$, have been shown to increase HYAL1 expression and activity in multiple cell types via activation of NF- $\kappa$ B pathway. ${ }^{80,83,84}$ Moreover, early growth response 1 , a master transcription factor that coordinates endothelial activation and that has been reported to be up-regulated in diabetic endothelium, binds to the promoter in HYAL1 -expressing cells, ${ }^{84}$ including endothelial cells. ${ }^{85,86}$ It is 


\section{Quiescent}

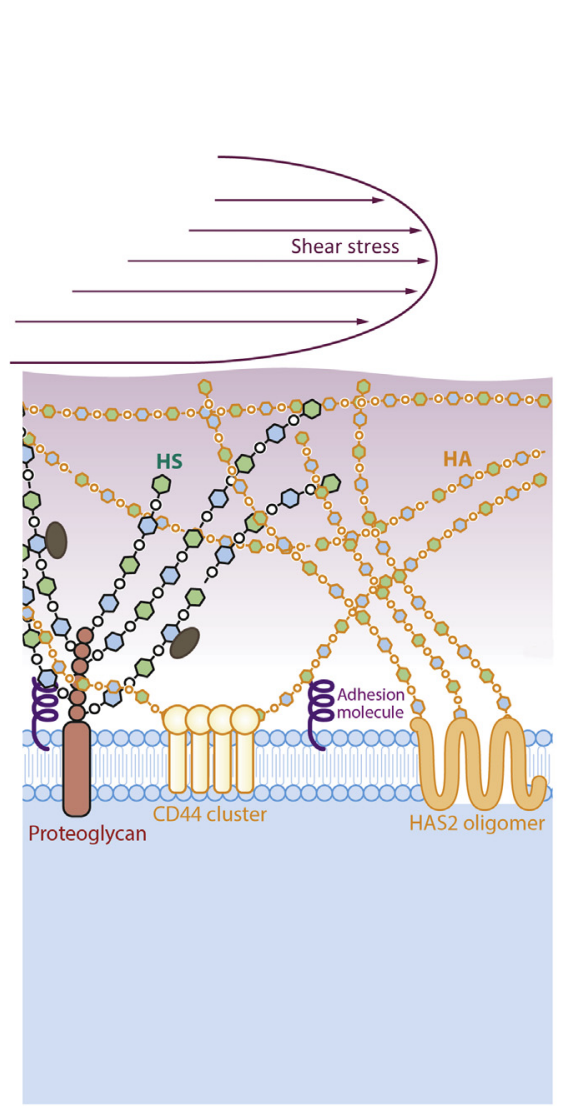

Activated

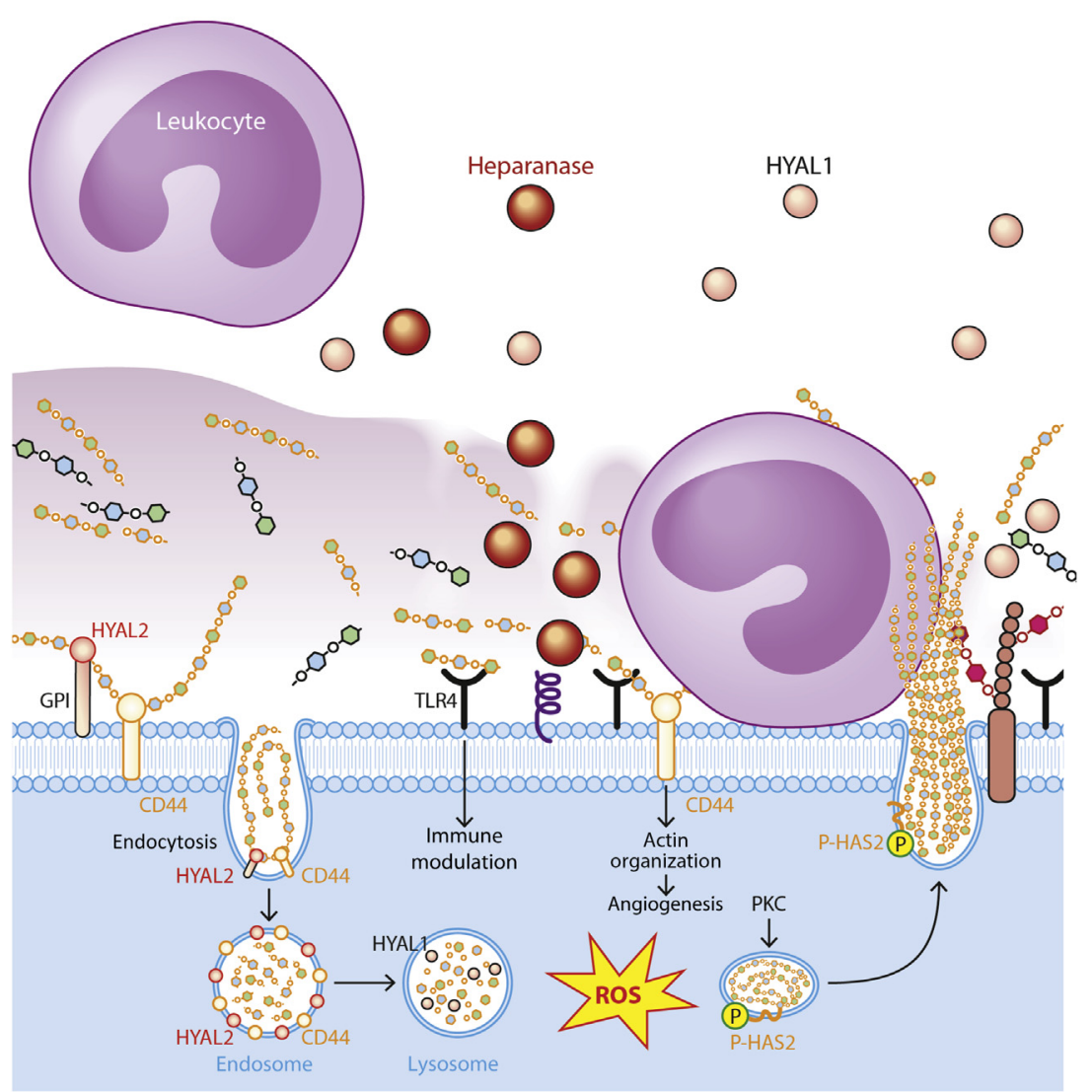

Figure 3 Schematic overview of hyaluronan (HA) metabolism disorder results in the endothelial glycocalyx dysfunction in diabetes. Left panel: In a physiological state, the dynamic metabolism of HA regulated by laminar shear stress keeps the endothelial glycocalyx integrity and protects against endothelial dysfunction. Long polymeric hyaluronan is interwoven with proteoglycan-bound polysaccharides, such as heparan sulfate (HS). Direct access to the cell membrane for circulating factors and cells is shielded, and specific binding domains in the polysaccharides generate gradients of growth factors and chemokines that together with the shear-sensing properties of this layer determine endothelial cell behavior. Right panel: In diabetes, the glycocalyx layer is degraded by heparanase and hyaluronidases (HYALs). HA biosynthesis in activated endothelial cells now leads to increased intracellularly HA-cabled structures. Together with increased HYAL2 activity, this could lead to excess HA degradation and accumulation of longer HA fragments extracellularly. These can also be further degraded into small HA oligosaccharides by HYAL1 in lysosomes. These fragments can increase inflammation and angiogenesis through association with toll-like receptor 4 (TLR4) and CD44, respectively. In addition, the released HA aggresomes on the membrane attract monocyte adhesion. This generalized $\mathrm{HA}$ metabolism dysregulation leads to the endothelial glycocalyx damage and vascular destabilization, which can contribute to the development of vascular complications in diabetes. GPI, glycosylphosphatidylinositol; P-HAS2, phosphorylated-HAS2; PKC, protein kinase C; ROS, reactive oxygen species.

therefore likely that the altered oxidation-reduction state and ensuing microinflammation are directly related to the induction of hyaluronidases and loss of the glycocalyx. As discussed before, circulating plasma HYAL1 can possibly be endocytosed and activated by endothelial cells, ${ }^{4}$ which may contribute to the generalized glycocalyx dysfunction induced by diabetes. In addition, in concert with HYAL2, cell migration-inducing hyaluronidase 2 could also play a role in endothelial surface HA loss, although its regulation in diabetes is still unknown. ${ }^{43}$

\section{Endothelial Hyaluronan as a Pharmacologic Target}

Preserving and restoring the endothelial glycocalyx HA could be a potent drug target to prevent diabetic organ complications. Druggable targets may include the biosynthesis of HA as well its degradation through hyaluronidases.

Increased vascular endothelial growth factor A levels have been demonstrated in the development of diabetic retinopathy and early diabetic nephropathy. By counteracting the vascular endothelial growth factor A effect, vascular endothelial growth factor $\mathrm{C}$ treatment reduces the development of early diabetic nephropathy and protects against albuminuria in an endothelial glycocalyx-dependent manner by increasing glomerular endothelial HA synthesis. ${ }^{87,88}$ Interestingly as a hypoglycemic drug, metformin improves the endothelial glycocalyx in $\mathrm{db} / \mathrm{db}$ mice. ${ }^{89}$ It is also shown to protect endothelial function in diet-induced obese mice by inhibition of endoplasmic reticulum stress through activating AMPK. ${ }^{90}$ The metformin-regulated endoplasmic reticulum stress inhibition and AMPK activation could be postulated to also have a beneficial effect on endothelial HA biosynthesis. 
Activation of hyaluronidases is one of the main causes of HA shedding in diabetes. Inhibition of HYAL1 activity has also been considered as another strategy to prevent the endothelial glycocalyx damage in diabetes. HYAL1 deficiency dramatically increases HA incorporation into the endothelial glycocalyx and results in a thicker glycocalyx layer in 4-week streptozotocin-induced diabetic mice. ${ }^{37}$ It also prevents diabetes-induced endothelial dysfunction and glomerular barrier dysfunction. ${ }^{37}$ HYAL1 deficiency also potentially decrease the local accumulation of HA fragments in lesion area of diabetes. ${ }^{37}$ In this aspect, HYAL1 inhibitors could be developed and used as a therapeutic approach to prevent the early stage of vascular complication in diabetes. However, complete HYAL1 deficiency causes pathologic storage of mucopolysaccharide in lysosomes of histiocytes and fibroblasts, named as mucopolysaccharidosis IX, in both human and mouse, ${ }^{39,91}$ although a gene dose dependency of this severe phenotype has been described as well. ${ }^{39}$ HYAL2deficient mice show increased markers of endothelial damage and microvascular fibrin deposition, which induces thrombotic microangiopathy with hemolytic anemia. ${ }^{35}$ These phenotypes point to the complexity of hyaluronidase inhibition, particularly with respect to the therapeutic window. Sulodexide, a mix of HS and dermatan sulfate supplied as GAG precursor, increases the endothelial glycocalyx and also reduces the plasma HYAL1 activity in type 2 diabetic patients. ${ }^{67}$ However, it failed to demonstrate renoprotection in overt type 2 diabetic nephropathy patients. ${ }^{92}$

The use of antioxidants has been shown to effectively increase the endothelial glycocalyx and preserve endothelial function on stimulation in human and animal models. ${ }^{93-95}$ Infusion of the antioxidant $N$-acetylcysteine could prevent the acute hyperglycemia-induced reduction of endothelial HA and increase the endothelial glycocalyx volume in healthy people. ${ }^{93}$

\section{Conclusion}

Endothelial HA plays a critical role in glycocalyx integrity and endothelial homeostasis. In physiological circumstances, the balance between HA biosynthesis and catabolism is in a dynamic equilibrium, where glycocalyx functions are maintained. The presence of HA in the glycocalyx is a prerequisite for (micro)vascular stability through both its mechanosensitive properties as well as its role as a matrix for vascular stability factors, such as angiopoietin 1. Loss of endothelial HA consequently leads to microvascular disease, manifesting itself as glomerulopathy, retinopathy, and cardiomyopathy. ${ }^{7}$ In diabetes, the metabolic changes in endothelial cells lead to increased HA degradation, potentially increased intracellular HA-cable structures, and loss of glycocalyx function (Figure 3). Normalization of HA metabolism, including biosynthesis and catabolism, is therefore a potential therapeutic target for diabetes to prevent (micro) vascular disease.

\section{Author Contributions}

G.W., G.L.T., B.M.v.d.B., and T.J.R. wrote the manuscript; all authors contributed to discussions of the content and reviewed or edited the manuscript before submission.

\section{References}

1. Rix DA, Douglas MS, Talbot D, Dark JH, Kirby JA: Role of glycosaminoglycans (GAGs) in regulation of the immunogenicity of human vascular endothelial cells. Clin Exp Immunol 1996, 104: $60-65$

2. Dane MJ, van den Berg BM, Lee DH, Boels MG, Tiemeier GL, Avramut MC, van Zonneveld AJ, Van der Vlag J, Vink H, Rabelink TJ: A microscopic view on the renal endothelial glycocalyx. Am J Physiol Renal Physiol 2015, 308:F956-F966

3. Reitsma S, Slaaf DW, Vink H, van Zandvoort MA, oude Egbrink MG: The endothelial glycocalyx: composition, functions, and visualization. Pflugers Arch 2007, 454:345-359

4. Dogne S, Flamion B, Caron N: Endothelial glycocalyx as a shield against diabetic vascular complications: involvement of hyaluronan and hyaluronidases. Arterioscler Thromb Vasc Biol 2018, 38: $1427-1439$

5. Esko JD, Selleck SB: Order out of chaos: assembly of ligand binding sites in heparan sulfate. Annu Rev Biochem 2002, 71:435-471

6. Lennon FE, Singleton PA: Hyaluronan regulation of vascular integrity. Am J Cardiovasc Dis 2011, 1:200-213

7. van den Berg BM, Wang G, Boels MGS, Avramut MC, Jansen E, Sol WMPJ, Lebrin F, van Zonneveld AJ, de Koning EJP, Vink H, Gröne H-J, Carmeliet P, van der Vlag J, Rabelink TJ: Glomerular function and structural integrity depend upon hyaluronan synthesis by glomerular endothelium. J Am Soc Nephrol 2019, 30:1886-1897

8. van den Berg BM, Spaan JA, Vink H: Impaired glycocalyx barrier properties contribute to enhanced intimal low-density lipoprotein accumulation at the carotid artery bifurcation in mice. Pflugers Arch 2009, 457:1199-1206

9. Rabelink TJ, van den Berg BM, Garsen M, Wang G, Elkin M, van der Vlag J: Heparanase: roles in cell survival, extracellular matrix remodelling and the development of kidney disease. Nat Rev Nephrol 2017, 13:201-212

10. Itano N, Sawai T, Yoshida M, Lenas P, Yamada Y, Imagawa M, Shinomura T, Hamaguchi M, Yoshida Y, Ohnuki Y, Miyauchi S, Spicer AP, McDonald JA, Kimata K: Three isoforms of mammalian hyaluronan synthases have distinct enzymatic properties. J Biol Chem 1999, 274:25085-25092

11. Mambetsariev N, Mirzapoiazova T, Mambetsariev B, Sammani S, Lennon FE, Garcia JG, Singleton PA: Hyaluronic acid binding protein 2 is a novel regulator of vascular integrity. Arterioscler Thromb Vasc Biol 2010, 30:483-490

12. Torronen K, Nikunen K, Karna R, Tammi M, Tammi R, Rilla K Tissue distribution and subcellular localization of hyaluronan synthase isoenzymes. Histochem Cell Biol 2014, 141:17-31

13. Jacobson A, Brinck J, Briskin MJ, Spicer AP, Heldin P: Expression of human hyaluronan synthases in response to external stimuli. Biochem J 2000, 348:29-35

14. Siiskonen H, Oikari S, Pasonen-Seppanen S, Rilla K: Hyaluronan synthase 1: a mysterious enzyme with unexpected functions. Front Immunol 2015, 6:43

15. Rilla K, Oikari S, Jokela TA, Hyttinen JM, Karna R, Tammi RH, Tammi MI: Hyaluronan synthase 1 (HAS1) requires higher cellular UDP-GlcNAc concentration than HAS2 and HAS3. J Biol Chem 2013, 288:5973-5983

16. Moretto P, Karousou E, Viola M, Caon I, D'Angelo ML, De Luca G, Passi A, Vigetti D: Regulation of hyaluronan synthesis in vascular diseases and diabetes. J Diabetes Res 2015, 2015:167283 
17. DeAngelis PL, Weigel PH: Immunochemical confirmation of the primary structure of streptococcal hyaluronan synthase and synthesis of high molecular weight product by the recombinant enzyme. Biochemistry 1994, 33:9033-9039

18. Tlapak-Simmons VL, Baron CA, Weigel PH: Characterization of the purified hyaluronan synthase from Streptococcus equisimilis. Biochemistry 2004, 43:9234-9242

19. Vigetti D, Viola M, Karousou E, De Luca G, Passi A: Metabolic control of hyaluronan synthases. Matrix Biol 2014, 35:8-13

20. Vigetti D, Ori M, Viola M, Genasetti A, Karousou E, Rizzi M, Pallotti F, Nardi I, Hascall VC, De Luca G, Passi A: Molecular cloning and characterization of UDP-glucose dehydrogenase from the amphibian Xenopus laevis and its involvement in hyaluronan synthesis. J Biol Chem 2006, 281:8254-8263

21. Baggenstoss BA, Harris EN, Washburn JL, Medina AP, Nguyen L, Weigel PH: Hyaluronan synthase control of synthesis rate and hyaluronan product size are independent functions differentially affected by mutations in a conserved tandem B-X7-B motif. Glycobiology 2016, 27:154-164

22. Oikari S, Kettunen T, Tiainen S, Hayrinen J, Masarwah A, Sudah M, Sutela A, Vanninen R, Tammi M, Auvinen P: UDP-sugar accumulation drives hyaluronan synthesis in breast cancer. Matrix Biol 2018, 67:63-74

23. Wang G, Kostidis S, Tiemeier GL, Sol WMPJ, de Vries MR, Giera M, Carmeliet P, van den Berg BM, Rabelink TJ: Shear stress regulation of endothelial glycocalyx structure is determined by glucobiosynthesis. Arterioscler Thromb Vasc Biol 2020, 40:350-364

24. Vigetti D, Deleonibus S, Moretto P, Karousou E, Viola M, Bartolini B, Hascall VC, Tammi M, De Luca G, Passi A: Role of UDP-N-acetylglucosamine (GlcNAc) and O-GlcNAcylation of hyaluronan synthase 2 in the control of chondroitin sulfate and hyaluronan synthesis. J Biol Chem 2012, 287:35544-35555

25. Vigetti D, Deleonibus S, Moretto P, Bowen T, Fischer JW, Grandoch M, Oberhuber A, Love DC, Hanover JA, Cinquetti R, Karousou E, Viola M, D'Angelo ML, Hascall VC, De Luca G, Passi A: Natural antisense transcript for hyaluronan synthase 2 (HAS2-AS1) induces transcription of HAS2 via protein O-GlcNAcylation. J Biol Chem 2014, 289:28816-28826

26. Karousou E, Kamiryo M, Skandalis SS, Ruusala A, Asteriou T, Passi A, Yamashita H, Hellman U, Heldin CH, Heldin P: The activity of hyaluronan synthase 2 is regulated by dimerization and ubiquitination. J Biol Chem 2010, 285:23647-23654

27. Vigetti D, Clerici M, Deleonibus S, Karousou E, Viola M, Moretto P, Heldin P, Hascall VC, De Luca G, Passi A: Hyaluronan synthesis is inhibited by adenosine monophosphate-activated protein kinase through the regulation of HAS2 activity in human aortic smooth muscle cells. J Biol Chem 2011, 286:7917-7924

28. Weigel PH: Hyaluronan synthase: the mechanism of initiation at the reducing end and a pendulum model for polysaccharide translocation to the cell exterior. Int J Cell Biol 2015, 2015:367579

29. Fraser JR, Laurent TC, Laurent UB: Hyaluronan: its nature, distribution, functions and turnover. J Intern Med 1997, 242:27-33

30. Lebel L: Clearance of hyaluronan from the circulation. Adv Drug Deliv Rev 1991, 7:221-235

31. Csoka AB, Scherer SW, Stern R: Expression analysis of six paralogous human hyaluronidase genes clustered on chromosomes 3p21 and 7q31. Genomics 1999, 60:356-361

32. Stern R: Hyaluronan catabolism: a new metabolic pathway. Eur J Cell Biol 2004, 83:317-325

33. Wang YZ, Cao ML, Liu YW, He YQ, Yang CX, Gao F: CD44 mediates oligosaccharides of hyaluronan-induced proliferation, tube formation and signal transduction in endothelial cells. Exp Biol Med 2011, 236:84-90

34. Campo GM, Avenoso A, D'Ascola A, Prestipino V, Scuruchi M, Nastasi G, Calatroni A, Campo S: Hyaluronan differently modulates TLR-4 and the inflammatory response in mouse chondrocytes. BioFactors 2012, 38:69-76
35. Onclinx C, Dogne S, Jadin L, Andris F, Grandfils C, Jouret F, Mullier F, Flamion B: Deficiency in mouse hyaluronidase 2: a new mechanism of chronic thrombotic microangiopathy. Haematologica 2015, 100:1023-1030

36. Jadin L, Wu X, Ding H, Frost GI, Onclinx C, Triggs-Raine B, Flamion B: Skeletal and hematological anomalies in HYAL2deficient mice: a second type of mucopolysaccharidosis IX? FASEB J 2008, 22:4316-4326

37. Dogne S, Rath G, Jouret F, Caron N, Dessy C, Flamion B: Hyaluronidase 1 deficiency preserves endothelial function and glycocalyx integrity in early streptozotocin-induced diabetes. Diabetes 2016, 65: $2742-2753$

38. van den Berg BM, Vink H, Spaan JA: The endothelial glycocalyx protects against myocardial edema. Circ Res 2003, 92:592-594

39. Natowicz MR, Short MP, Wang Y, Dickersin GR, Gebhardt MC, Rosenthal DI, Sims KB, Rosenberg AE: Clinical and biochemical manifestations of hyaluronidase deficiency. N Engl J Med 1996, 335: $1029-1033$

40. Yoshida H, Nagaoka A, Kusaka-Kikushima A, Tobiishi M, Kawabata K, Sayo T, Sakai S, Sugiyama Y, Enomoto H, Okada Y, Inoue S: KIAA1199, a deafness gene of unknown function, is a new hyaluronan binding protein involved in hyaluronan depolymerization. Proc Natl Acad Sci U S A 2013, 110:5612-5617

41. Yamamoto $\mathrm{H}$, Tobisawa $\mathrm{Y}$, Inubushi $\mathrm{T}$, Irie $\mathrm{F}$, Ohyama $\mathrm{C}$, Yamaguchi Y: A mammalian homolog of the zebrafish transmembrane protein 2 (TMEM2) is the long-sought-after cell-surface hyaluronidase. J Biol Chem 2017, 292:7304-7313

42. Michishita E, Garces G, Barrett JC, Horikawa I: Upregulation of the KIAA1199 gene is associated with cellular mortality. Cancer Lett 2006, 239:71-77

43. Yamaguchi Y, Yamamoto H, Tobisawa Y, Irie F: TMEM2: a missing link in hyaluronan catabolism identified? Matrix Biol 2019, 78-79: 139-146

44. Uchiyama H, Dobashi Y, Ohkouchi K, Nagasawa K: Chemical change involved in the oxidative reductive depolymerization of hyaluronic acid. J Biol Chem 1990, 265:7753-7759

45. Yamazaki K, Fukuda K, Matsukawa M, Hara F, Yoshida K, Akagi M, Munakata H, Hamanishi C: Reactive oxygen species depolymerize hyaluronan: involvement of the hydroxyl radical. Pathophysiology 2003, 9:215-220

46. Soltes L, Mendichi R, Kogan G, Schiller J, Stankovska M, Arnhold J: Degradative action of reactive oxygen species on hyaluronan. Biomacromolecules 2006, 7:659-668

47. Rees MD, Hawkins CL, Davies MJ: Hypochlorite-mediated fragmentation of hyaluronan, chondroitin sulfates, and related N-acetyl glycosamines: evidence for chloramide intermediates, free radical transfer reactions, and site-specific fragmentation. J Am Chem Soc 2003, 125:13719-13733

48. Fan J, Sun Y, Xia Y, Tarbell JM, Fu BM: Endothelial surface glycocalyx (ESG) components and ultra-structure revealed by stochastic optical reconstruction microscopy (STORM). Biorheology 2019, 56: 77-88

49. Henry CB, Duling BR: Permeation of the luminal capillary glycocalyx is determined by hyaluronan. Am J Physiol 1999, 277: H508-H514

50. Gao L, Lipowsky HH: Composition of the endothelial glycocalyx and its relation to its thickness and diffusion of small solutes. Microvasc Res 2010, 80:394-401

51. Mochizuki S, Vink H, Hiramatsu O, Kajita T, Shigeto F, Spaan JA, Kajiya F: Role of hyaluronic acid glycosaminoglycans in shearinduced endothelium-derived nitric oxide release. Am J Physiol 2003, 285:H722-H726

52. Potter DR, van Teeffelen J, Vink H, van den Berg BM: Perturbed mechanotransduction by endothelial surface glycocalyx modification greatly impairs the arteriogenic process. Am J Physiol 2015, 309: H711-H717 
53. Dyer DP, Thomson JM, Hermant A, Jowitt TA, Handel TM, Proudfoot AE, Day AJ, Milner CM: TSG-6 inhibits neutrophil migration via direct interaction with the chemokine CXCL8. J Immunol 2014, 192:2177-2185

54. Johnson P, Ruffell B: CD44 and its role in inflammation and inflammatory diseases. Inflamm Allergy Drug Targets 2009, 8: 208-220

55. Singleton PA, Dudek SM, Ma SF, Garcia JGN: Transactivation of sphingosine 1-phosphate receptors is essential for vascular barrier regulation: novel role for hyaluronan and CD44 receptor family. J Biol Chem 2006, 281:34381-34393

56. Cao G, Savani RC, Fehrenbach M, Lyons C, Zhang L, Coukos G, Delisser HM: Involvement of endothelial CD44 during in vivo angiogenesis. Am J Pathol 2006, 169:325-336

57. Savani RC, Cao G, Pooler PM, Zaman A, Zhou Z, DeLisser HM: Differential involvement of the hyaluronan (HA) receptors CD44 and receptor for HA-mediated motility in endothelial cell function and angiogenesis. J Biol Chem 2001, 276:36770-36778

58. Park D, Kim Y, Kim H, Kim K, Lee YS, Choe J, Hahn JH, Lee H, Jeon J, Choi C, Kim YM, Jeoung D: Hyaluronic acid promotes angiogenesis by inducing RHAMM-TGF beta receptor interaction via CD44-PKC delta. Mol Cells 2012, 33:563-574

59. Shurer CR, Kuo JC, Roberts LM, Gandhi JG, Colville MJ, Enoki TA, Pan H, Su J, Noble JM, Hollander MJ, O'Donnell JP, Yin R, Pedram K, Mockl L, Kourkoutis LF, Moerner WE, Bertozzi CR, Feigenson GW, Reesink HL, Paszek MJ: Physical principles of membrane shape regulation by the glycocalyx. Cell 2019, 177: 1757-1770.e21

60. Kubota T, Kubota N, Kumagai H, Yamaguchi S, Kozono H, Takahashi $\mathrm{T}$, et al: Impaired insulin signaling in endothelial cells reduces insulin-induced glucose uptake by skeletal muscle. Cell Metab 2011, 13:294-307

61. Eskens BJ, Mooij HL, Cleutjens JP, Roos JM, Cobelens JE, Vink H, Vanteeffelen JW: Rapid insulin-mediated increase in microvascular glycocalyx accessibility in skeletal muscle may contribute to insulin-mediated glucose disposal in rats. PLoS One 2013, 8:e55399

62. Eskens BJM, Cobelens HE, Vink H, VanTeeffelen JWGE: Acute enzymatic glycocalyx degradation results in reduced insulin sensitivity but normal glucose tolerance in conscious rats. Cardiovasc Endocrinol 2014, 3:66-73

63. Nawroth PP, Isermann B: Mechanisms of diabetic nephropathy-old buddies and newcomers part 2. Exp Clin Endocrinol Diabetes 2010, 118:667-672

64. Nawroth PP, Isermann B: Mechanisms of diabetic nephropathy-old buddies and newcomers part 1. Exp Clin Endocrinol Diabetes 2010, 118:571-576

65. Nieuwdorp M, Mooij HL, Kroon J, Atasever B, Spaan JA, Ince C, Holleman F, Diamant M, Heine RJ, Hoekstra JB, Kastelein JJ, Stroes ES, Vink H: Endothelial glycocalyx damage coincides with microalbuminuria in type 1 diabetes. Diabetes 2006, 55:1127-1132

66. Nieuwdorp M, Holleman F, de Groot E, Vink H, Gort J, Kontush A, Chapman MJ, Hutten BA, Brouwer CB, Hoekstra JB, Kastelein JJ, Stroes ES: Perturbation of hyaluronan metabolism predisposes patients with type 1 diabetes mellitus to atherosclerosis. Diabetologia 2007, 50:1288-1293

67. Broekhuizen LN, Lemkes BA, Mooij HL, Meuwese MC, Verberne H, Holleman F, Schlingemann RO, Nieuwdorp M, Stroes ES, Vink H: Effect of sulodexide on endothelial glycocalyx and vascular permeability in patients with type 2 diabetes mellitus. Diabetologia 2010, 53:2646-2655

68. Brownlee M: The pathobiology of diabetic complications: a unifying mechanism. Diabetes 2005, 54:1615-1625

69. Buse MG: Hexosamines, insulin resistance, and the complications of diabetes: current status. Am J Physiol Endocrinol Metab 2006, 290: $\mathrm{E} 1-\mathrm{E} 8$
70. Little JM, Kurkela M, Sonka J, Jantti S, Ketola R, Bratton S, Finel M, Radominska-Pandya A: Glucuronidation of oxidized fatty acids and prostaglandins B1 and E2 by human hepatic and recombinant UDPglucuronosyltransferases. J Lipid Res 2004, 45:1694-1703

71. Okamura K, Ishii Y, Ikushiro S, Mackenzie PI, Yamada H: Fatty acyl-CoA as an endogenous activator of UDP-glucuronosyltransferases. Biochem Biophys Res Commun 2006, 345:1649-1656

72. Rask-Madsen C, King GL: Vascular complications of diabetes: mechanisms of injury and protective factors. Cell Metab 2013, 17: 20-33

73. Treps L, Conradi LC, Harjes U, Carmeliet P: Manipulating angiogenesis by targeting endothelial metabolism: hitting the engine rather than the drivers-a new perspective? Pharmacol Rev 2016, 68:872-887

74. Katsumura C, Sugiyama T, Nakamura K, Obayashi H, Hasegawa G, Oku H, Ikeda T: Effects of advanced glycation end products on hyaluronan photolysis: a new mechanism of diabetic vitreopathy. Ophthalmic Res 2004, 36:327-331

75. Vigetti D, Genasetti A, Karousou E, Viola M, Moretto P, Clerici M, Deleonibus S, De Luca G, Hascall VC, Passi A: Proinflammatory cytokines induce hyaluronan synthesis and monocyte adhesion in human endothelial cells through hyaluronan synthase 2 (HAS2) and the nuclear factor-kappaB (NF-kappaB) pathway. J Biol Chem 2010, 285:24639-24645

76. Hascall VC, Majors AK, De La Motte CA, Evanko SP, Wang A, Drazba JA, Strong SA, Wight TN: Intracellular hyaluronan: a new frontier for inflammation? Biochim Biophys Acta 2004, 1673:3-12

77. Vigetti D, Genasetti A, Karousou E, Viola M, Clerici M, Bartolini B, Moretto P, De Luca G, Hascall VC, Passi A: Modulation of hyaluronan synthase activity in cellular membrane fractions. J Biol Chem 2009, 284:30684-30694

78. de la Motte C, Nigro J, Vasanji A, Rho H, Kessler S, Bandyopadhyay S, Danese S, Fiocchi C, Stern R: Platelet-derived hyaluronidase 2 cleaves hyaluronan into fragments that trigger monocyte-mediated production of proinflammatory cytokines. Am J Pathol 2009, 174:2254-2264

79. Kong X, Chen L, Ye P, Wang Z, Zhang J, Ye F, Chen S: The role of HYAL2 in LSS-induced glycocalyx impairment and the PKAmediated decrease in eNOS-Ser-633 phosphorylation and nitric oxide production. Mol Biol Cell 2016, 27:3972-3979

80. Flannery CR, Little CB, Hughes CE, Caterson B: Expression and activity of articular cartilage hyaluronidases. Biochem Biophys Res Commun 1998, 251:824-829

81. Monzon ME, Fregien N, Schmid N, Falcon NS, Campos M, Casalino-Matsuda SM, Forteza RM: Reactive oxygen species and hyaluronidase 2 regulate airway epithelial hyaluronan fragmentation. J Biol Chem 2010, 285:26126-26134

82. Ikegami-Kawai M, Okuda R, Nemoto T, Inada N, Takahashi T: Enhanced activity of serum and urinary hyaluronidases in streptozotocin-induced diabetic Wistar and GK rats. Glycobiology 2004, 14:65-72

83. Monzon ME, Manzanares D, Schmid N, Casalino-Matsuda SM, Forteza RM: Hyaluronidase expression and activity is regulated by pro-inflammatory cytokines in human airway epithelial cells. Am J Respir Cell Mol Biol 2008, 39:289-295

84. Lokeshwar VB, Gomez P, Kramer M, Knapp J, McCornack MA, Lopez LE, Fregien N, Dhir N, Scherer S, Klumpp DJ, Manoharan M, Soloway MS, Lokeshwar BL: Epigenetic regulation of HYAL-1 hyaluronidase expression: identification of HYAL-1 promoter. J Biol Chem 2008, 283:29215-29227

85. Olofsson B, Porsch H, Heldin P: Knock-down of CD44 regulates endothelial cell differentiation via NFkappaB-mediated chemokine production. PLoS One 2014, 9:e90921

86. Karthikkeyan G, Nareshkumar RN, Aberami S, Sulochana KN, Vedantham S, Coral K: Hyperglycemia induced early growth response-1 regulates vascular dysfunction in human retinal endothelial cells. Microvasc Res 2018, 117:37-43 
87. Onions KL, Gamez M, Buckner NR, Baker SL, Betteridge KB, Desideri S, Dallyn BP, Ramnath RD, Neal CR, Farmer LK, Mathieson PW, Gnudi L, Alitalo K, Bates DO, Salmon AHJ, Welsh GI, Satchell SC, Foster RR: VEGFC reduces glomerular albumin permeability and protects against alterations in VEGF receptor expression in diabetic nephropathy. Diabetes 2019, 68:172-187

88. Foster RR, Armstrong L, Baker S, Wong DW, Wylie EC, Ramnath R, Jenkins R, Singh A, Steadman R, Welsh GI, Mathieson PW, Satchell SC: Glycosaminoglycan regulation by VEGFA and VEGFC of the glomerular microvascular endothelial cell glycocalyx in vitro. Am J Pathol 2013, 183:604-616

89. Eskens BJ, Zuurbier CJ, van Haare J, Vink H, van Teeffelen JW: Effects of two weeks of metformin treatment on whole-body glycocalyx barrier properties in $\mathrm{db} / \mathrm{db}$ mice. Cardiovasc Diabetol 2013, 12: 175

90. Cheang WS, Tian XY, Wong WT, Lau CW, Lee SS, Chen ZY, Yao X, Wang N, Huang Y: Metformin protects endothelial function in diet-induced obese mice by inhibition of endoplasmic reticulum stress through 5' adenosine monophosphate-activated protein kinaseperoxisome proliferator-activated receptor delta pathway. Arterioscler Thromb Vasc Biol 2014, 34:830-836
91. Martin DC, Atmuri V, Hemming RJ, Farley J, Mort JS, Byers S, Hombach-Klonisch S, Csoka AB, Stern R, Triggs-Raine BL: A mouse model of human mucopolysaccharidosis IX exhibits osteoarthritis. Hum Mol Genet 2008, 17:1904-1915

92. Packham DK, Wolfe R, Reutens AT, Berl T, Heerspink HL, Rohde R, Ivory S, Lewis J, Raz I, Wiegmann TB, Chan JC, de Zeeuw D, Lewis EJ, Atkins RC; Collaborative Study Group: Sulodexide fails to demonstrate renoprotection in overt type 2 diabetic nephropathy. J Am Soc Nephrol 2012, 23:123-130

93. Nieuwdorp M, van Haeften TW, Gouverneur MC, Mooij HL, van Lieshout MH, Levi M, Meijers JC, Holleman F, Hoekstra JB, Vink H, Kastelein JJ, Stroes ES: Loss of endothelial glycocalyx during acute hyperglycemia coincides with endothelial dysfunction and coagulation activation in vivo. Diabetes 2006, 55:480-486

94. Constantinescu AA, Vink H, Spaan JA: Elevated capillary tube hematocrit reflects degradation of endothelial cell glycocalyx by oxidized LDL. Am J Physiol 2001, 280:H1051-H1057

95. Marechal X, Favory R, Joulin O, Montaigne D, Hassoun S, Decoster B, Zerimech F, Neviere R: Endothelial glycocalyx damage during endotoxemia coincides with microcirculatory dysfunction and vascular oxidative stress. Shock 2008, 29:572-576 